\title{
Test rig for stand-alone small power wind turbine emulation for variable wind and load
}

\author{
C. Vlad, A. Burlibaşa, T. Munteanu, G. Gurguiatu and M. Barbu \\ Automatic Control and Electrical Engineering Department \\ Faculty of Automatic control, Computers, Electrical Engineering and Electronics \\ "Dunărea de Jos" University of Galaţi, \\ 47, Domnească, 800008-Galaţi, Romania \\ Tel: 0040-336-130-108; e-mail: ciprian.vlad@ugal.ro, adriana.scarlat@ugal.ro,toader.munteanu@ugal.ro, \\ gelu.gurguiatu@ugal.ro,marian.barbu@ugal.ro
}

\begin{abstract}
This paper presents futures from experimental investigation of an autonomous small power wind system. The envisaged wind system is based on a PMSG (Permanent Magnet Synchronous Generator) directly connected to the wind turbine shaft, while the DC output load is supplied by a rectifier and a chopper. The DC load is considered as a resistive load with wide values range. Experimental investigations are provided in partial load regime. The power optimization is performed through a power loop in two ways: by controlling the electrical power or by controlling the electromechanical power.

For the above two situations it is shown how the optimization power loop reference and power loop feedbacks can be set, in order to obtain maximum electrical power, for each wind speed value corresponding to the partial load regime.

It was also highlighted that for a wide range of DC load values the mechanical and electrical powers are not constant as it should be corresponding to the mathematical model of the optimal conversion. This is due to mechanic-electrical subsystem processes. The electrical power variation range with the load should be provided by the manufacturer in the low-power wind system data sheet.
\end{abstract}

\section{Key words}

small wind energy conversion system, autonomous low power wind system, power point tracking, PMSG

\section{Introduction}

The main EU directives regarding electrical power supply from renewable sources, particularly from wind speed, requires to each member states an imposed shear. Besides high-power wind systems, the low-power wind systems are important especially for island locations.

According to the technical literature, small systems architecture is based mainly on PMSG, fixed pitch and variable speed operation [1], [2], [3]. At high wind speed values, the power captured is limited at the rated value with passive stall control technique.
For grid connected wind turbines the electrical power optimization in partial load regime, performed for wind speed within cut-in and nominal values, is done through mechanical power maximization [4], [5], [6]. The generator (mechanic-electrical subsystem) has a nearly constant efficiency, the only exogenous variable which modifies the mechanical power being the wind speed.

At low-powers, the PMSG external characteristics are strongly falling [7]. In this paper [7] has been shown that, at low wind power systems, in energy conversion chain the PMSG electromechanical converter properties matters. Taking this into account, the electrical power maximization may not be ensured by maintaining the tip speed ratio at the optimal value, $\lambda(\mathrm{t})=\lambda_{\text {opt }}$, [4], [5]. This can be done through a particular solution for electrical power maximization.

The mechanical power developed by a wind turbine is given by:

$$
P_{m}=0.5 \rho \pi R^{2} v^{3} C_{p}(\lambda)
$$

where: $\rho$ - air density; $R$ - blade length, $v$ - wind speed and $C_{p}$ - power coefficient.

Wind turbine power efficiency is given by the power coefficient which depends on the tip speed ratio, $\lambda$, defined as the ratio between the peripheral blade speed and the wind speed: $\lambda=R \Omega / v$.

The $C_{p}(\lambda)$ performance curve has a maximum at the optimal tip speed ratio $\left(\lambda_{\text {opt }}\right)$. At this vale the operating points are kept on the optimal regime characteristic (ORC) which corresponds to the maximum power values [4]. Clearly explain the nature of the problem, previous work, purpose and contribution of the paper. 


\section{Theoretical aspects}

The approached wind system has the structure presented in the Figure 1. It can be seen two control inner loops (the current and shaft rotational speed loops) and an outer electromechanical power loop. The PMSG is directly connected to the wind turbine shaft. It feeds the DC-link through a diode rectifier and a buck converter. The wind power system load can be adjusted by the chopper output. Practically the wind system is composed from two subsystems, a mechanical subsystem and an electrical one, see the dashed framed parts from figure 1. In partial load regime, corresponding to wind speed between cut-in and nominal values, the chopper input, $\alpha$, must ensure the optimal wind energy conversion for various values of wind speed and/or the local grid load.

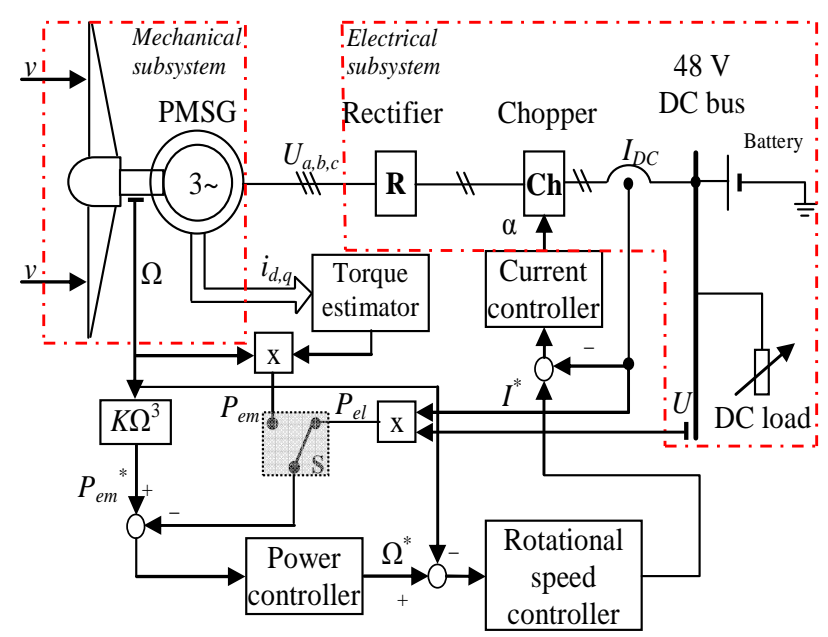

Fig. 1. Autonomous wind power system structure.

The power control loop setpoint is given by the following expression [4], [7]:

$$
P_{e m}^{*}=K \Omega^{3}
$$

When the power optimization is performed in relation with the electromechanical power, $K$ must be set to the value given by:

$$
\mathrm{K}=\mathrm{K}_{\mathrm{opt}}=\frac{1}{2} \rho \pi \frac{C_{p}\left(\lambda_{\text {opt }}\right)}{\lambda_{\text {opt }}^{3}} R^{5}
$$

The power loop feedback can be the electromechanical power, case when the two subsystems from figure 1 are not interacting, and the electrical power, case when the two subsystems are interacting. The feedback is chosen through the switch $\mathrm{S}$ from figure 1. The electromechanical power, $P_{e m}$, from the control loop, is given by the product between the estimated electromagnetic torque, $T_{e m}$, and the measured shaft rotational speed, $\Omega$. The electrical power is given by the product between the DC current and voltage. When the wind speed increases, the power controller imposes the increase of the rotational speed setpoint, $\Omega *$. This gives a displacement to the right of the operating point. At its turn the rotational speed controller sets the reference for the current controller.

\section{Experimental rig}

The wind energy conversion system (WECS) are systems for which the real-world validation of various control laws through off-line simulations involves new technical approaches unconcern the outside wind speed, but in controlled wind speed regime [8], [9].

The experimental rig, which comprises the analyzed wind system, is a multi-source autonomous hybrid system. This is composed of: a diesel engine, batteries, a wind system, an inverter, DC and AC loads. The wind turbine shaft is directly coupled to Southwest Windpower ${ }^{\circledR}$ Whisper WHI 200 PMSG. It contains also a Whisper ${ }^{\circledR}$ voltage charge controller, a charge controller NC25AFlexcharge ${ }^{\circledR}$, and 4 batteries BTL 12-200, de $12 \mathrm{~V}$ and 200 Ah. The Danfoss ${ }^{\circledR}$ VLT 5005 Flux Inverter controllers an asynchronous motor with $960 \mathrm{rot} / \mathrm{min}$ rated speed and $3 \mathrm{~kW}$ rated power. This means that wind turbines of $3 \mathrm{~kW}$ maximum rated power can be simulated [10].

The electromechanical wind turbine simulator is build based upon the „Hardware-In-the-Loop” - HIL simulation concept [4], [11], [12].

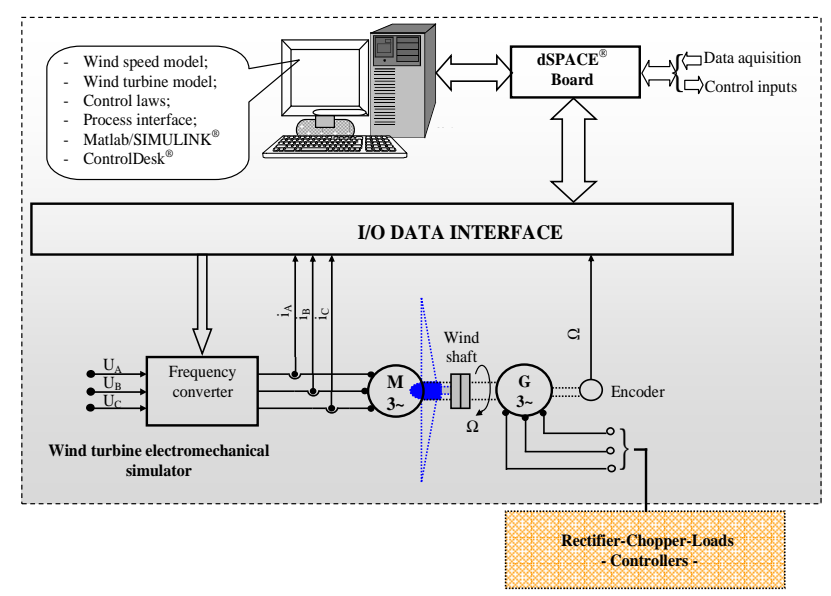

Fig. 2. Block diagram of the experimental rig.

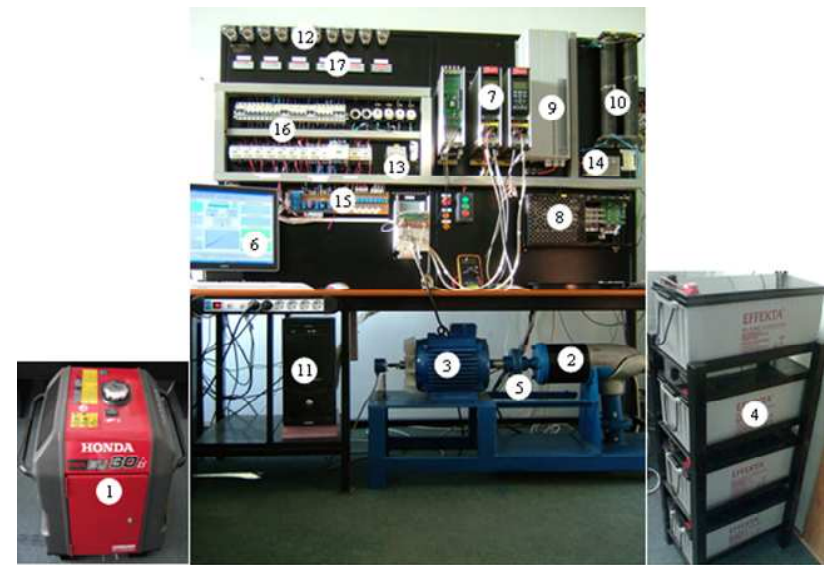

Fig. 3. The experimental rig: 1 - diesel engine; 2 - PMSG; 3 asynchronous motor; 4 - batteries; 5 - wind shaft; 6 - software (Matlab/Simulink $^{\circledR}$, ControlDesk ${ }^{\circledR}$ ); 7 - frequency converter; 8 Whisper controller; 9 - inverter; 10 - DC load; 11 - workstation with dSPACE ${ }^{\circledR}$ board; 12 - AC load; 13 - Flexcharge controller; 14 - power supply for transducers; 15 - current and voltage transducers; 16 - circuit brakers, fuses; 17 - measurements units. 
The hardware/software support of the whale rig is ensured by the dSPACE ${ }^{\circledR}$ board DS 1103 . The rig monitoring is possible due to the control desk interface.

The experimental rig, represented in Figure 2, is composed of two subsystems: an electromechanical wind turbine simulator and a load adaptation circuit in order to ensure operation on the ORC. The detailed physical structure is given in Figure 3.

\section{Experimental results}

Often, the DC load is not a battery but a local grid. In these conditions, a resistance that varies very widely was considered as the DC bus load on.

The main goals of the paper consist in analysing the:

- wind system operation when the power loop setpoint is given by (2), $\mathrm{K}$ parameter by (3) and the power loop feedback is the electromechanical power or the electrical power. the adjustment of the $\mathrm{K}$ parameter value has been closely studied in order to obtain the optimal regime when the electrical power is used as feedback;

- wind systems behaviour at variable wind speed and load.

Parameters in relation to which the system is analized are: 1. wind speed; 2 . K coefficient from relation (3) which gives the optimal power setpoint with the rotational speed in partial-lod regime; 3. DC local load.

The total load resistance, $R_{s}$, is composed from 6 parallel resistors, each of them having $12.6 \mathrm{ohms}$, so, at a $48 \mathrm{~V}$ DC bus voltage the maximum electrical power can be consumed. 6 values of the load were considered: 12.6; $12.6 / 2 ; 12.6 / 3 ; 12.6 / 4 ; 12.6 / 5$ and $12.6 / 6$ ohms in the experimental investigations.

The first goal of this paper is detailed in the following. From Figure 4 one can see the dependence between the electromechanical power (dashed line) or electrical power (solid line) and $\mathrm{K}$ parameter, for a constant wind speed value and load $\left(R_{s}=2.1\right.$ ohms, $\left.v=9 \mathrm{~m} / \mathrm{s}\right)$. Maximum electromechanical power value, corresponding to the point A from figure 4 , was obtained with $\mathrm{K}$ from relation (3).

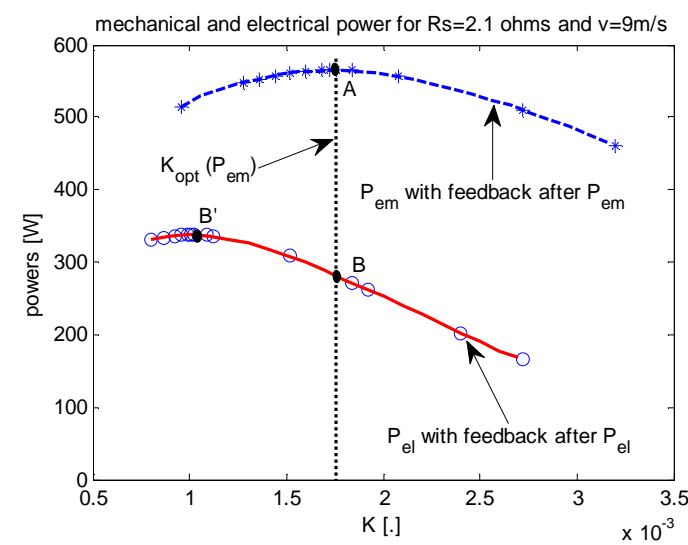

Fig. 4. Power characteristics at constant load and wind speed (usual case)
As one can see, in this case, when $\mathrm{K}=\mathrm{K}_{\mathrm{opt}}$, the operating point $\mathrm{B}$ of the electrical power characteristic is slightly different than the operating point B' (see figure 4).

The maximum electrical power value corresponding to the operating point B' can be reached in two ways:

1 - either a mechanical power reference it is used, case when $\mathrm{K}_{\mathrm{opt}}$ is known, but the electromechanical power feedback is obtained based on the estimated electromagnetic torque;

2 - either a mechanical power reference it is used, with unknown $\mathrm{K}$, while the power feedback is stated after the electrical power.

The results presented in figure 5 correspond to case 1 . The advantage of this case is the fact that the maximum of the electrical power (see point B" which has the same coordinate as point B') when it is used a power loop reference with known $\mathrm{K}=\mathrm{K}_{\mathrm{opt}}$. As one can see the ordinates of B' and B', operating points are the same and correspond to the maximum value of the electrical power. These values are obtained at different power optimization references. The drawback of this case consists in a higher cost due to the electromagnetic torque estimator used for electromechanical power computation.

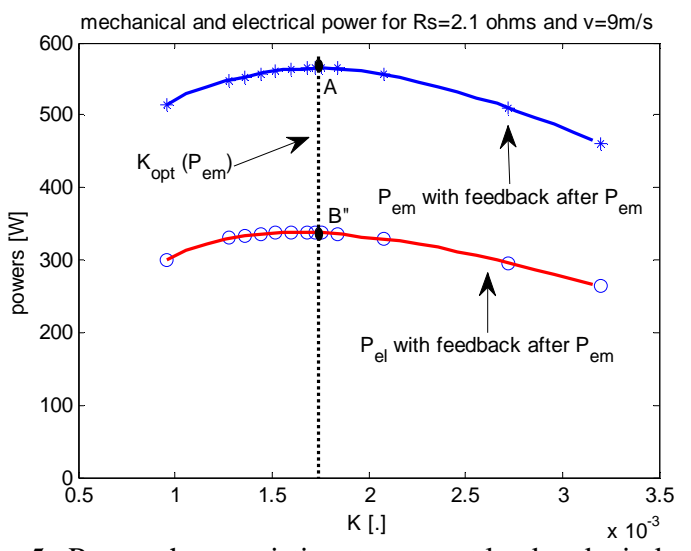

Fig. 5. Power characteristics at constant load and wind speed (case 1)

The results presented in figure 6 correspond to case 2 . The main advantage of this case is the fact that the power loop feedback is the electrical power, a signal easy to be measured.

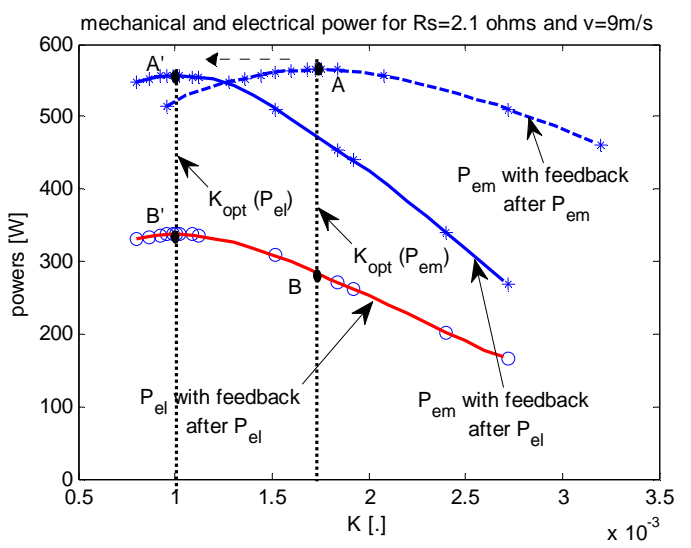

Fig. 6. Power characteristics at constant load and wind speed (case 2) 
The value of $\mathrm{K}$ parameter must be found in order to ensure maximum electrical and electromechanical power. This is the drawback of this case. Even if $\mathrm{K}$ is different, the maximum values of the mechanical power are the same (see A and A' points). B' marks the same maximum value of the electrical power as point B" from figure 5 , even if the $\mathrm{K}$ is different.

Usually, wind systems are analyzed in relation to wind speed and rarely in relation to the load variation. Further, it is shown the powers behavior with the load variation, at constant wind speed. These results were obtained when the feedback power optimization loop is the electromechanical power generated as a function of the estimated electromagnetic torque.

In Figure 7, DC grid voltage and current variation are represented, when the resistive load is changing $\left(R_{s}\right)$, in case of two wind speed values ( 5 and $9 \mathrm{~m} / \mathrm{s}$ ) and for two values of the tip speed ratio ( 7 and 8 ). The $\lambda=7=\lambda_{\text {opt }}$ is the optimal value for which the mechanical power is maximal. It is found that the variations are non-linear, which suggests that at constant wind speeds, $v=c t$, and $\mathrm{K}=0.0016$ which corresponds to optimal power conversion (the mechanical power is maximal at every wind speed), the electrical and mechanical powers are varying. This can be observed in Figure 8. Thus, at low loads the mechanical power is high and the electrical power is minimal. At high loads the electrical power is high and the mechanical power is low.
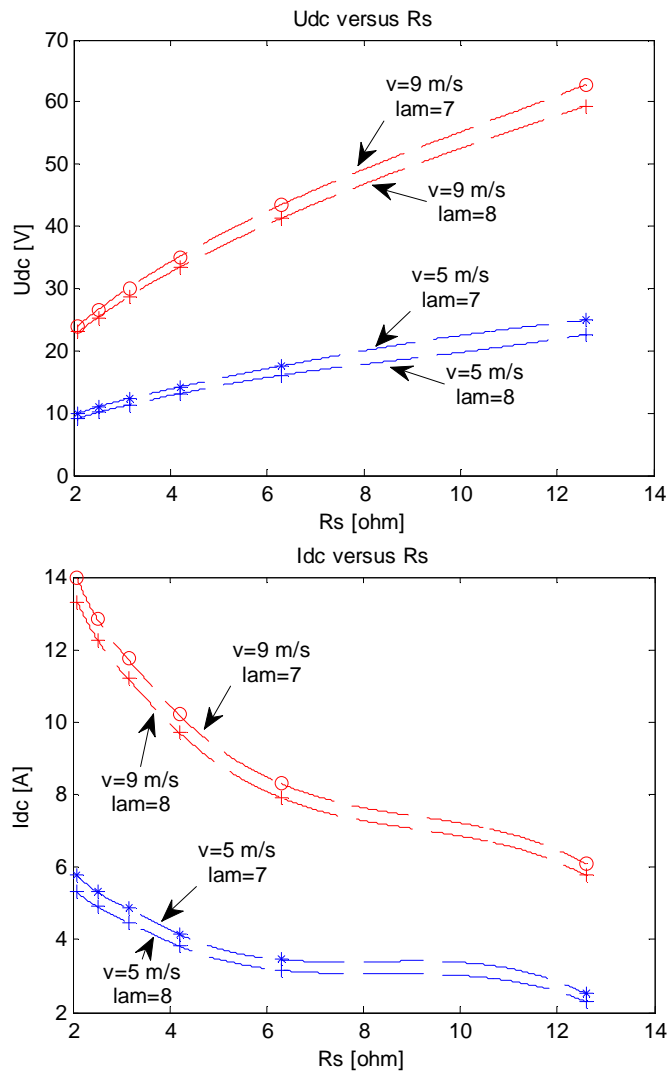

Fig. 7. DC voltage and current variations with load. The experimental points are marked with "*”, "+"” and "o".
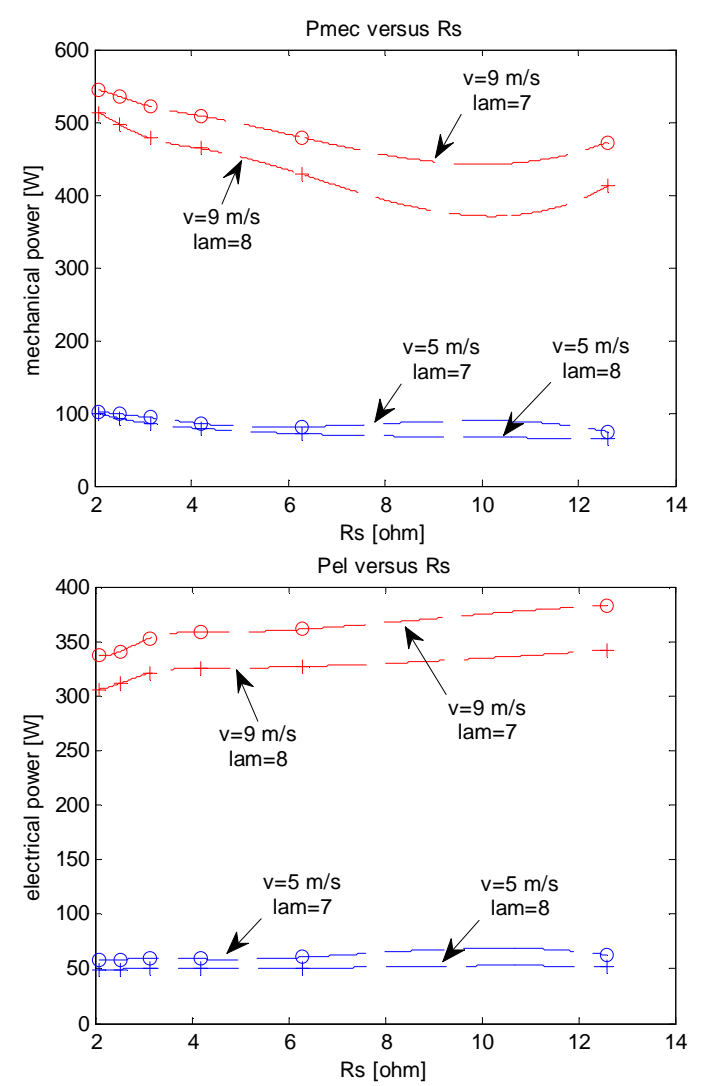

Fig. 8. Mechanical and electrical power variations with load for two wind speed and tip speed ration $(v=5$ and $9 \mathrm{~m} / \mathrm{s} ; \lambda=\mathrm{lam}=7$ and 9). The experimental points are marked with "*”, "+” and "o").

The explanation of this result is the following: at constant wind speed and fixed $K$ parameter the mechanical power should be constant (see relation (1)) and the electrical power also. In fact, the load variation produces current variation that gives changes in iron and copper losses, so at small load resistances the electrical power decreases. Mechanical power variation is due to the interaction of the two subsystems of the wind system: wind-mechanical and mechanical-electrical.

\section{Conclusion}

The power optimization loop can have as feedback either the estimated electromechanical power, either the measured electrical power. The loop reference can be established in relation with shaft rotational speed cube, with the $\mathrm{K}$ parameter at the optimal value $\mathrm{K}_{\mathrm{opt}}$ or at a different value then this.

In this paper are highlighted two proper solution for power loop optimization employing: first when the electromechanical power as loop feedback and $\mathrm{K}$ is known $\left(\mathrm{K}=\mathrm{K}_{\mathrm{opt}}\right)$ and second when the electrical power is the feedback of the optimization loop and $\mathrm{K}<\mathrm{K}_{\text {opt }}$ The first case has the advantage that there is no uncertainty about fixing the power reference, but the drawback is that an estimator torque must be employed. Instead, in the second case the measured electrical power used as feedback is an advantage, with the disadvantage that the parameter $\mathrm{K}$ must be experimentally established based on some test during commissioning of the experimental wind 
system. According to the financial possibilities, the user can choose one of these options

An experimental rig, as the one presented in this paper, is very useful in testing wind systems, because its tests do not depend on the outside meteorological conditions (wind speed). Here, one can set and impose the wind profile and this makes this tool suitable for research in automatic control of wind systems.

\section{Acknowledgement}

This work was supported by a grant of the Romanian National Authority for Scientific Research, CNDIUEFISCDI, project number PN-II-PT-PCCA-2011-3.21680 .

\section{References}

[1] K. Tan, S. Islam. (2004). Optimum control strategies in energy conversion of PMSG wind turbine system without mechanical sensors. IEEE Transactions on Energy Conversion. 19(2). pp. 392-399.

[2] T. Senjiyu, S. Tamaki, E. Muhando, N. Urasaki, H. Kijo, T. Funabashi, H. Fujita, H. Sekine. (2006). Wind velocity and rotor position sensorless maximum power point tracking control for wind generation system. Renewable Energy. 31. pp. 1764-1775.

[3] H. Camblong, I. Martinez de Alegria, M. Rodriguez, G. Abad. (2006). Experimental evaluation of wind turbines maximum power point tracking controllers. Energy Conversion and Management. 47(18-19), pp. 2846-2858.
[4] I. Munteanu, A.I. Bratcu, N.A. Cutululis, E. Ceangă, Optimal Control of Wind Energy Systems - Towards a Global Approach. Springer-Verlag, London, 2008.

[5] T. Burton, D. Sharpe, N. Jenkins, E. Bossanyi, Wind energy handbook. John Wiley \& Sons, New-York, 2001.

[6] F. Bianchi, H. De Battista, R.J. Mantz, Wind turbine control systems - Principles, modelling and gain scheduling design. Springer-Verlag, London, 2006.

[7] C. Vlad, I. Munteanu, A.I. Bratcu, E. Ceangă, Output power maximization of low-power wind energy conversion systems revisited: Possible control solutions, Energy Conversion and Management, 51(2) 2010 305-310.

[8] C. Nichita, D. Luca, B. Dakyo, E. Ceangă, Large Band Simulation of the Wind Speed for Real Time Wind Turbine Simulators, IEEE Transactions on Energy Conversion 17(4) (2002) 523-529.

[9] M. Monfared, H.M. Kojabadi, H. Rastegar, Static and dynamic wind turbine simulator using a converter controlled dc motor, Renewable Energy 33 (2008) 906-913.

[10] C. Vlad, I. Munteanu, A. I. Bratcu, I. Bivol, E. Ceangă, Development System for Experimental Research of Hybrid Renewable Energy Systems, The Second International Symposium on Electrical and Electronics Engineering ISEEE-2008, ISSN 1842-8046, 2008, Galati, Romania.

[11] U. Kiffmeier, A Hardware-in-the-Loop Testbench for ABS Controllers, presented at the Conference on Control and Diagnostics in Automotive Applications 1996, Genova, Italy.

[12] M. Ouhrouche, Transient analysis of a grid connected wind driven induction generator using a real-time simulation platform, Renewable Energy 34 (2009) 801-806. 